\title{
Indoor Thermal Environment in Tropical Climate Residential Building
}

\author{
Nazhatulzalkis Jamaludin ${ }^{1}$, Mohd Faris Khamidi ${ }^{2}$, Suriani Ngah Abdul Wahab ${ }^{3}$, Mustafa M.A. \\ Klufallah $^{4}$ \\ 1,2,3,4 Department of Civil Engineering, Faculty of Engineering, Universiti Teknologi Petronas, Bandar \\ Seri Iskandar, 37150 Tronoh Perak, Malaysia
}

\begin{abstract}
Indoor thermal environment is one of the criteria in sustainable building. This criterion is important in ensuring a healthy indoor environment for the occupants. The consideration of environmental concerns at the early design stage would effectively integrate the sustainability of the building environment. Global climate changes such as global warming do affect human comfort since people spend most of their time and activities in the building. The increasing of urban population required additional housing for households, as well as places to shop, office and other facilities. Occupants are now more conscious the importance of sustainability for a better quality of life. Good thermal environment is essential for human wellness and comfort. A residential environment will influence residents' health and safety. The global warming increase the earth's temperature and greenhouse emission to the atmosphere cause adverse effects to the outdoor environment. Residential developments modify the materials, structure and energy balance in urban climate effects of human economic activities. As an indoor environment is influenced by the outdoor condition, the factors affecting indoor thermal environment are crucial in improving a comfortable and healthy environment in residential building. The microclimatic of a site such as temperature and relative humidity, and wind movement led to the variation of indoor thermal environment in the building.
\end{abstract}

\section{Introduction}

Development activities on the needs of social and economic growth have an impact on global environmental issues in recent years. Unprecedented increase in global temperature is attributed to higher rates of greenhouse gas emission from human activities. Global warming contribute to ecological system problems such as reduction of the ozone layer, acid rain, forest and agricultural land can destroy the economic, social and political, and thus could affect national security internationally [1]. Al Khidir and Zailani [2] discussed that climate change, global warming and extreme weather conditions have now threatened human and ecosystem sustainability. Moreover the increasing of world population presents confronts in providing sustainable residential building facing declining natural resources and climate change stated by. Residential developments modify the materials, structure and energy balance especially in the urban environment which become the centre of economic activities. Urbanization change the urban climate from natural to man-made and alter the 
atmosphere composition that differ from suburban and rural natural environment [3]. The urban temperatures varied in accordance with land uses and urban environment became too hot in the daytimes hours. This situation indicates the excess heat load and the present of urban heat island. This phenomenon will deteriorate the urban physical and human environment with the increasing the used of energy consumption for comfortable indoor environment [3,4]. In the tropical region, climatic factor notably affects the microclimate and indoor thermal comfort in a building. Challenges in sustainable buildings are to reduce the input of resources such as energy, materials and water and waste production. The aim of sustainable building is to improve the quality of the building indoor environment without compromise the impact to the environment. Hence, adapting the sustainable development concept design as strategies to residential building can improve the indoor thermal comfort and healthy environment. A survey of the current literature on the issue of sustainable development has urged the building industry to take significant efforts without compromising the environment

\section{Sustainable Building Environment}

Sustainability is the ability of providing future generation needs without compromising present necessities for the continuity of the human and natural environment. In the built environment, awareness of the sustainable development has increased, resulting in the environmental assessment of building performance to be certified as a green building. In this assessment the main outcome is to produce a healthy living indoor environment meanwhile conserving natural resources and reducing negative impact to the natural environment. The human environment is human-modified places and composed of either a single building or groups of buildings, structures and infrastructures [5]. Building industry as one of the major industries in the world had a significant impact on the living environment and ecosystems. Sustainable building perspective makes the environmental issues related to building design of most importance. As the physical characteristic of climate related to thermal comfort, the selection of climate modification strategies should be adopted in a building design basis. A sustainable building is one which is designed:

1. To save energy and resources consumption, recycle materials and minimize the emission of toxic constituent throughout its life cycle.

2. To harmonize with the local climate, traditions, culture and the immediate environment,

3. To sustain and improve the quality of human life and maintaining the capacity of the ecosystem at the local and global levels [6]

Choi and $\mathrm{Yu}$ discussed that the eastern cultural design currently has been recognized as healthy environment designs that accomplish sustainability in human environment [7]. Traditional building design and construction were considered as climate responsive design in mitigating current climatic problems. In order to integrate the sustainable design with the combination of techniques and natural principles, they are being reconstructed and reconsidered in encountering the human quality of life.

\section{Tropical Climate and Its Building Context}

Tropical region known with warm and humid climate condition lies within the Tropics of Cancer and Capricorn between latitude of $15^{\circ}$ South and $15^{\circ}$ North. These regions cover the areas of Malaysia, Singapore, Indonesia, Philippines, India and northern Australia, part of Africa and Latin America. Tropical climate generally characterized as high humidity, abundance of rainfall and large amount solar radiation. A building is an enclosure for the improvement of human habitation, employment or recreation. A building in the tropics means a confrontation of construction and function with extreme climatic condition [8,9]. The climatic elements in tropical climate have both negative impact and positive impact to the building design. The most common impacts caused by the climatic parameters of tropical climate are temperature, relative humidity, solar radiation, rainfall and prevailing wind. 
High humidity and temperatures reduce moisture evaporation rate from the human skin. In achieving thermal comfort, cooling effects and ventilation are always necessary. In tropical climate the solar heat and rainfall initiate continuous evaporation of the human body due to high amount of solar radiation received in the equatorial region. These excessive solar radiations cause discomfort condition of indoor environment in buildings. Solar control design should be incorporated into building to reduce heat surplus from solar radiation. The optimum orientation of residential building area in tropical climate is facing east or north and its major openings can greatly influence the solar heat gain[10]. North and east orientation has less direct solar direction towards the building envelope. More windows should be placed at this orientation in order to allow natural ventilation. In the indoor environment, natural ventilation the strategies could be the categorized into cross ventilation, singlesided ventilation and stack ventilation to induce air movement in the building[11]. Wind movement is the source for natural cooling strategy in the tropics. Low or still air movement with high temperature and relative humidity can cause thermal discomfort. Wind might be unpredictable parameter and variations in its velocity, thus the building orientation towards the direction of the local prevailing wind will enhance the natural ventilation for cooling purposes. Buildings in warm and humid climate should be open and filter the climate in a multitude of ways that requires optimization of the relationship between the site, climate and briefing requirements. Kondrat'ev and Volkov [12] in their study suggest that open-design apartment is the variant for minimizing the space, makes use the space in an optimal way and creates a feeling of wide spaces and convenient. Tropical climate dominated by high rainfall and there is one or two dry seasons in a year. Heavy rainfall at periods of the year and high temperatures increased the relative humidity. The concern of the openings design in tropical climate is also to avoid the penetration of rain and strong wind. Heavy and frequent rainfall in urban areas would cause to flash flood and other environmental problem. Drainage system from roof and paved surfaces is important for water runoff because it will influence traffic flow in urban areas. Maintaining green areas and microclimate strategies within surrounding urban areas can improve indoor thermal comfort condition [13]. Passive strategies make use of climatic elements to adopt modification in building design that response to local climate characteristics [14].

\section{Indoor Thermal Environment in Residential Building}

In designing comfortable room condition, there are many factors need to be considered. These factors are including microclimate condition such as humidity, radiant temperature, air temperatures, air movement, and human physiological aspects like body metabolic rate, level of activity and clothing of the occupants. Good indoor thermal condition will create comfortable (without heat stress or thermal strain for the occupants) and healthy environment to sustain occupants' living quality. Thermal comfort is one of the basic physical and biological needs of human. The human body temperature needs to be maintained at a constant $37 \pm 5^{\circ} \mathrm{C}$ regardless of the prevailing ambient condition. It is important to keep thermal conditions in buildings within acceptable limits in maintaining maximum human productivity and performance. The indoor thermal environment are much affected by local climate, and air movement through the building is necessary to decrease indoor discomfort due to overheating conditions in tropical climate [15]. İndoor thermal environment much affected by environmental factors such as air temperature, air movement, humidity and radiation. İn warm and humid climate, external air movement assist in controlling the indoor environment [16]. Recently occupants are likely to use air conditioners in achieving comfortable indoor environment in tropical climate. The reliant on mechanical systems for health and comfort level has increasing the energy consumption in residential building [17]. The buildings sector consumed the large amount of energy during the utilization phase of the building for heating and cooling purposes [18]. Therefore, the initial stage of building design should given priority in order to reduce the amount of energy consumed during the utilization phase throughout buildings lifecycle. Yoshino et al(2006) in their calculation of space heating and cooling loads of the apartments in Beijing shows that thermal 
insulation and airtightness are effective ways, to control energy conservation for space heating in residential sector [19]. Jamaludin et al. (2013) found that linear arrangement of building layout has restricted the employment of daylighting and natural ventilation in the room and affected the indoor comfort level of the occupants [20]. The optimization of climate response building would help to improve indoor thermal environment and reduce energy consumption. The large ratio of external window area/ external wall area increases the penetration of solar radiation into building. The orientation of buildings during the design phase in mitigating solar heat gain and an important factor for saving the energy cost of the buildings [18].

\section{Sustainable Design Principles of Traditional House in Tropical Climate}

The housing characteristics can be distinguished according to a region and culture of its local people. The factors such as climate, building materials, economical and cultural background reflects the house design (Hutchison, 2002). The Malay traditional house was some example of vernacular architecture in the past that is environmentally sustainable [21]. The design and the construction process of traditional Malay architectural practice had applied the sustainable building criteria in term of energy efficiency, the quality of indoor environment, sustainable site planning and management, the materials and resources used [22]. The climatic design of the Malay traditional house in response to the microclimate and materials available provides the house with cooler environment and aids thermal comfort to the occupants. The houses are raised on stilts to allow ventilation at occupant body level. The traditional Malay house made of local sustainable building materials such as bamboo, softwood, hardwoods, tree barks and Nipah palm (nypa fruitican) leaves usually available from the tropical forest [23]. The effective adaptation of environmental factors in the traditional house design reflected the sensitivity of Malay people in the past in understanding climate responsive design approaches [24]. Traditional Malay house encourages a dynamic integration of local society, cultural and environmental necessities [25]. There were many numbers of windows in Malay vernacular houses and the design applied the maximum height of the wall to the floor, with fenestration at the top of the windows. This approach encourages cross air ventilation in promoting excellent indoor air quality and temperature in the house. This opening design promote the circulation of fresh air supply into the building, discharge pollutants inside the house and exchanged of used air [26]. Traditional Malay architecture appreciates climate which the outdoor expressions were responding to the exposure of the building surfaces or envelopes and their aesthetic effect of the sunlight and even the sky condition.

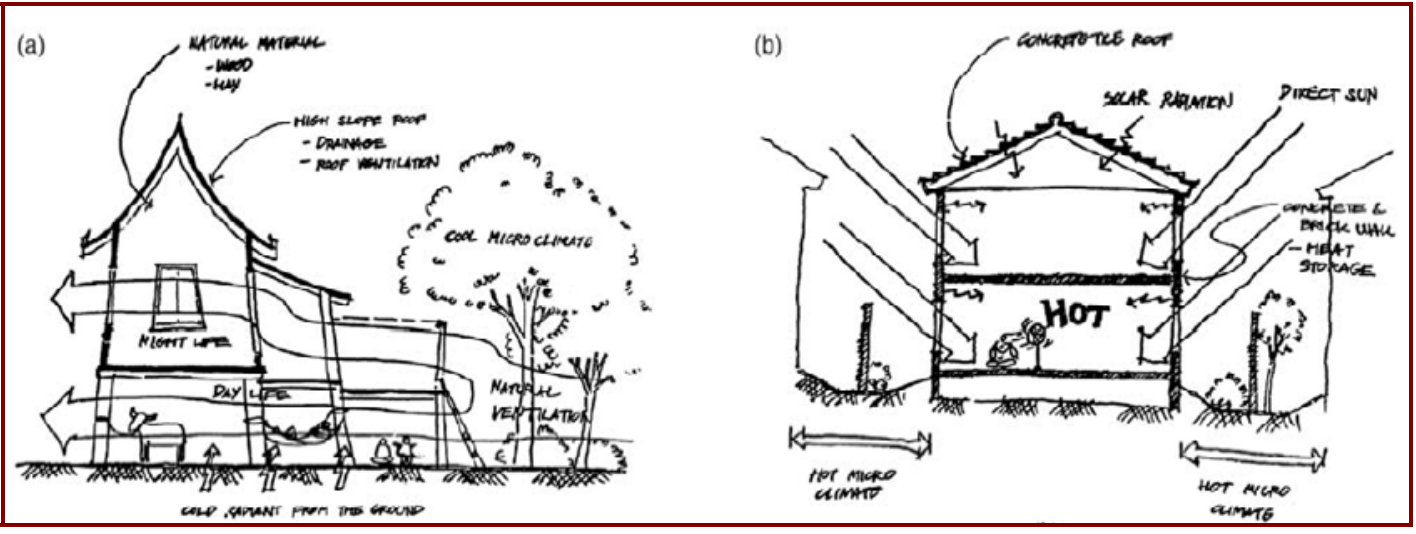

Figure 1 Sketch of typical tropical houses (a) traditional (b) modern.[29] 
Therefore it is important to continuously sustain the fundamental nature of climatic understanding into contemporary building design solution [27]. With a perusal and detail research by involving various knowledge disciplines such as mathematics, engineering, material and sociology and anthropology, the potential in this expanded traditional Malay house would be able to give a very mean contribution in planning and modern housing [28]. The thermal performance of building envelopes in tropical climate would be greatly affected by the amount of solar radiation that is absorbed and penetrated through the openings [29]. Building envelopes designs need to be considered in evaluating energy efficiency during the design process.

\section{Conclusion}

Occupants comfort and health are important in sustainable building design. The indoor thermal environment should be designed to maintain maximum human productivity and performance. In a warm and humid climate, indoor thermal performance will be improve by eliminate (if possible) heat surplus from solar radiation. The local climatic parameters have great influence in providing thermally comfortable environment. Climatic characteristics of a site have an obvious impact on building performance, especially its energy performance, indoor thermal environment and impacts on its surrounding. The key characteristics are temperature, humidity, air quality, potential pollution source, solar intensity, wind pattern, soil conditions and site drainage. Sustainable building design function impact to human productivity, building operational efficiency and effective use of natural resource. The integration of the building site location, building orientation and geometry, building envelope, layout arrangement and local climatic characteristics are all essential elements that have distinct impact on occupants' environment and building efficiency.

\section{References}

1. F. Azar, "Investigation on Reasons and Consequences of Climate Changes in International Systems," World Appl. Sci. J., vol. 25, no. 5, pp. 739-746, 2013.

2. T. AlKhidir and S. Zailani, "Going green in supply chain towards environmental sustainability," Glob. J. Environ. Res., vol. 3, no. 3, pp. 246-251, 2009.

3. A. Sharuddin, M. H. Noorazuan, M. J. Yaakob, A. Kadaruddin, and M. F. Mahamod, "The effects of different land uses on the temperature distribution of a humid tropical urban centre.pdf," World Appl. Sci. J., no. 13, pp. 63-68, 2011.

4. V. Puchkal and B. Jurmanov, "Stochastic Model of the Thermal Regime and Heat Consumption of Residential Buildings for Heating,” World Appl. Sci. J., vol. 23, no. 812, pp. 191-196, 2013.

5. H. Byrd and M. Ramli, Towards a sustainable built environment in Malaysia. Penang: Penerbit USM, 2012.

6. A.I.J Japan Architectural Institution, “Architecture for a Sustainable Future,” IBEC. 2005.

7. K. Choi and C. Yu, "Sustainable Design for Asian Housings : Traditional Culture , Lighting and," Indoor Built Environ., vol. 20, no. 5, pp. 485-487, 2011.

8. B. Givoni, Climate considerations in building and urban design. USA: Van Nostrand Reinhold, 1997, p. 109.

9. W. Lauber, Tropical Architecture: Sustainable and humane building in Africa, Latin America and South-East Asia. New York: Prestel Publishing, 2005.

10. K. Chauhan and N. Shah, "A study on Sustainable Urban Environment with climatic consideration in Housing Planning," Glob. J. Environ. Res., vol. 2, no. 1, pp. 12-17, 2008. 
11. L. P. Chung and M. H. Ahmad, "Application of CFD in Prediction of Indoor Building Thermal Performance as an Effective Pre-Design Tool Towards Sustainability Institute Sultan Iskandar of Urban Habitat and Highrise," World Appl. Sci. J., vol. 30, pp. 269-279, 2014.

12. L. Kondrat'eva and S. Volkov, "Minimizing the Residential Indoor Spaces for Comfort Living," World Appl. Sci. J., vol. 23, no. 812, pp. 207-211, 2013.

13. Z. Zain, M. Taib, and S. Baki, "Hot and humid climate: prospect for thermal comfort in residential building," Desalination, vol. 209, pp. 261-268, 2007.

14. R. Hyde, Climate responsive design - A study of buildings in moderate and hot humid climates. London: E \& FN Spon, 2000, p. 57.

15. I. Rajapaksha, H. Nagai, and M. Okumiya, "Indoor Thermal Modification of a Ventilated Courtyard House in the Tropics," J. Asian Archit. Build. Eng., vol. 1, no. 1, pp. 87-89, 2002.

16. T. Kubota and S. Ahmad, "Wind Environment Evaluation of Neighborhood Areas in Major Towns of Malaysia,” J. Asian Archit. Build. Eng., vol. 5, no. 1, pp. 199-206, 2006.

17. T. Uno, S. Hokoi, S. N. N. Ekasiwi, N. Hanita, and A. Majid, "Reduction of Energy Consumption by AC due to Air Tightness and Ventilation Strategy in Residences in Hot and Humid Climates," no. November, pp. 407-414, 2012.

18. E. Bostancioglu and B. Telatar, "Effect of Window Size on Residential Buildings' Energy Costs," World Appl. Sci. J., vol. 21, no. 4, pp. 631-640, 2013.

19. H. Yoshino, Y. Yoshino, Q. Zhang, A. Mochida, N. Li, Z. Li, and H. Miyasaka, "Indoor thermal environment and energy saving for urban residential buildings in China," Energy Build., vol. 38, no. 11, pp. 1308-1319, Nov. 2006.

20. A. A. Jamaludin, N. Keumala, A. R. Mohd Ariffin, and H. Hussein, "Satisfaction and perception of residents towards bioclimatic design strategies: Residential college buildings," Indoor Built Environ., May 2013.

21. C. A. Sufian and M. S. A. Rashid, "An analysis of the traditional malay architecture as indicators for sustainability: An introduction to its genius loci," in Proceeding of Arte-Polis 3rd International Conference on Creative Collaboration and the Making of Place, 2009.

22. N. Ramli, "House Thermal Comfort Design Elements into Modern Building Elements Case Study of Selangor Traditional Malay House \& Low Energy Building in Malaysia," Iran. J. Energy Environ., vol. 3, pp. 19-23, 2012.

23. P. Gibbs, Y. A. Rahman, and Z. Kassim, Building a Malay House. Singapore.: Oxford University Press, 1987, p. 99.

24. Tajul E. N., H. N. Husin, and K. K.S, "Climatic design feature in the traditional Malay house for ventilation purpose, Proceedings od International Seminar Malay Architecture as Lingua Franca, Jakarta, Indonesia, pp41-48.," in Proceedings od International Seminar Malay Architecture as Lingua Franca, 2005, pp. 41-48.

25. J. Y. Lim, The Malay House - Rediscovering Malaysia's Indigenous Shelter System. Penang, Malaysia. Penang, Malaysia: Institut Masyarakat, 1987.

26. N. Carslaw, "A new detailed chemical model for indoor air pollution.," Atmosph. Env., vol. 41, pp. 1164-1179, 2007.

27. M. H. Ahmad, "Can climate response become an essential lingua franca for Malay architecture?," in Seminar, International Architecture, Malay Franca, Lingua, 2005, pp. 1-7.

28. N. Utaberta, N. Spalie, and N. G. Abdullah, "Design Flexibility of Growing and Transformable House in Malaysia," Adv. Mater. Res., vol. 168-170, pp. 545-548, Dec. 2010.

29. N. a. M. Al-Tamimi and S. F. Syed Fadzil, "Thermal Performance Analysis for Ventilated and Unventilated Glazed Rooms in Malaysia (Comparing Simulated and Field Data)," Indoor Built Environ., vol. 20, no. 5, pp. 534-542, Jul. 2011. 